\title{
Temperature-associated suicide mortality: contrasting roles of climatic warming and the suicide prevention program in Finland
}

\author{
Samuli Helama $\cdot$ Jari Holopainen $\cdot$ Timo Partonen
}

Received: 25 September 2012/ Accepted: 16 January 2013/Published online: 5 February 2013

(C) The Japanese Society for Hygiene 2013

\begin{abstract}
Objectives Suicide is a notable cause of death worldwide, and while suicidal behavior appears to be associated with variations in temperature, no estimations are available of climate change impacts on suicide rates. The study aims to evaluate the influence of temperature on suicide mortality, especially on multi-decadal and longer time scales, that is, at scales on which the ongoing warming distinctly operates and is correspondingly appropriate for the current policy responses to warming climate.

Methods Our results are based on an extraordinarily long record of deaths from suicide in Finland from 1751 to 2008, and a similarly long climatic record of ambient temperatures correlative of environmental change in the study region.
\end{abstract}

Electronic supplementary material The online version of this article (doi:10.1007/s12199-013-0329-7) contains supplementary material, which is available to authorized users.

S. Helama $(\square)$

Arctic Centre, University of Lapland, P.O. Box 122,

96101 Rovaniemi, Finland

e-mail: samuli.helama@metla.fi

Present Address:

S. Helama

Finnish Forest Research Institute, Northern Unit, P.O. Box 16,

96301 Rovaniemi, Finland

J. Holopainen

Department of Geosciences and Geography,

University of Helsinki, P.O. Box 64, 00014 Helsinki, Finland

T. Partonen

National Institute for Health and Welfare,

P.O. Box 30, 00271 Helsinki, Finland
Results We show that temperature variability explains more than $60 \%$ of the total suicide variance up until the initiation of a national suicide prevention program. Despite ongoing warming, suicide rates have declined since the initiation of the program.

Conclusion By understanding the complexity of suicidal behavior as a response to ambient warming and the observed effects of interventions, our results underline the pressing need for a network of prevention programs to battle against temperature-mediated health hazards.

Keywords Environmental health - Preventive medicine . Suicide . Climatic change $\cdot$ Brown adipose tissue

\section{Introduction}

Since the time of Hippocrates it has been recognized that climate can deeply impact on health. Today this recognition is leading to a growing interest in assessing the potential influences of climate change on human health at global, national and local levels. Indeed, many prevalent diseases and health problems have been associated with climate-related fluctuations [1-3]. Relatively little evidence, however, has linked climatic warming with mental disorders and even less is known about the potential linkages between regional warming owing possibly to climatic change [4] and suicides. This was exposed in a literature review of quantitative analyses for the linkages between climate or weather and suicidal behavior [5]. Among 27 studies, ten found positive whereas four identified negative temperature associations. While a higher incidence of suicidal acts was found occurring on warm and sunny days in nine studies, six studies exhibited contradictory indications. The review [5] showed that our knowledge on the 
influence of climate and weather on suicidal behavior is still far from conclusive and in part contradictory.

Self-defeating behavior is a major public health problem across the world. Suicide is the tenth leading worldwide cause of deaths [6] insomuch that every $40 \mathrm{~s}$ one of us takes his or her own life. Nevertheless, the suicide rates are not temporally stable but show trends and variations of shorter term [6, 7]. Suicide and its prevention are receiving increasing worldwide attention [8]. Alarmingly high suicide rates in Finland during the 1970s and 1980s evoked a parliamentary committee on suicide, leading to a national suicide prevention program including a nationwide research phase during 1986-1991 followed by a nationwide implementation phase during 1992-1996 [9]. After 2 years of preliminary preparation, the program was started with a 1-year study of all the deaths from suicide in Finland, involving extensive data collection of all available information including both the medicolegal autopsy and the socalled psychological autopsy on each case. At the end of the research phase, the national suicide prevention target and action strategy was based on the data, published and distributed throughout Finland [10] (see http://www.stakes. fi/verkkojulkaisut/muut/mu161.pdf). Thus, the suicide prevention program was targeted at people with depression, substance use problems, in crisis situations or in need of psychological support due to physical illnesses and who had attempted suicide [9]. This combination of suicide research and prevention that was extended to the whole country was the first comprehensive effort of its kind [11].

The aim of this study was to statistically examine the extraordinarily long national suicide record of Finland since the mid-18th century, in order to provide a comprehensive assessment of both temperature changes and suicides in a country with high suicide mortality rates through age groups [12] and where temperatures are rising [13, 14]. This setting was further privileged by a correspondingly long climate record in the region $[15,16]$. We attempted to predict the impact of the prevention program on the suicide count by a simulation model under the association of the climatic influence on suicide mortality. Given the longtime role of climatic change [4], our analyses operate on decadal and longer scales. Understanding the compound response of suicidal behavior to ambient warming and intervention provides insights into therapeutic implications of prevention programs on the verge of 21 st century climatic change.

\section{Materials and methods}

Suicides have been registered by authorities in Finland since 1751 [17] (see Supplementary material, Table S1). A limitation of the data is that it provides annual figures and that the intra-annual (monthly) information is available only for irregular intervals (1851-1860, 1878-1935 and 1969 onwards). These data have been gathered by statistical authorities in Finland using the information from parish registers [12]. A death certificate written by a doctor became compulsory throughout the country in 1936, although a notification of death written by a layman could also be accepted if a doctor's certificate proved unreasonably difficult to obtain. It is known that by 1936 nearly $90 \%(88.4 \%)$ of all certificates were based on certificates by doctors [18]. After World War II, the situation was improved and between the years 1946 and 1950, the rate of death certificates was $94.5 \%$ and during the early $1950 \mathrm{~s}$ virtually all $(99.4 \%)$ deaths were certified by doctors [19, 20]. Since 1987, death certificate forms in Finland have complied with the recommendations of the World Health Organization's International Classification of Diseases [21]. The proportion of medicolegal investigations for suicide cases has been stable for many decades [12], and the overall autopsy rate has remained relatively high, both of which allow for reliable conclusions on suicide trends over time. The construction of the suicide time-series since 1751 is detailed in Holopainen et al. [17]. It follows that in this study, the suicide deaths are those that have been specified as such in the death certificates. Reliability of the data has supposedly improved since 1936, and especially since the 1950s.

Early climatic observations provided counterparts for the suicide data. We used the Uppsala temperature record because it is the longest continuous and homogenized temperature record in the geographical region of interest [16]. This temperature variability is highly correlative to the regional temperature variability over the entire study region and was used here as temperature. Correlations with the temperature record of Uppsala with temperatures in southern and northern Finland were as high as 0.942 $(p<0.01)$ and $0.782(p<0.01)$ as calculated for the shorter station records [22] of Helsinki (1890-2002) and Sodankylä (1908-2002), respectively. Moreover, the comparison between the long temperature history of Uppsala and the temperature record over the entire study region $\left(70-60^{\circ} \mathrm{N}, 20-30^{\circ} \mathrm{E}\right)$ as extracted from the global dataset [23] shows a coefficient of $0.908(p<0.01)$ between the years 1850 and 2005 (see Supplementary material, 1, Fig. S1).

The suicide counts were translated into suicide rates (per 100,000 persons) and the variance was stabilized using an established method [24]. The series was detrended using a stiff cubic spline that equals $67 \%$ of the series length [25]. Departures from the spline were accepted as residuals from the curve and normalized to $z$-scores having a mean of zero and a standard deviation of one. The Jarque-Bera statistic [26] was used to test the normal distribution of the data. The examined data were autocorrelated, and therefore the 
determinations of Pearson correlation coefficients were accompanied by their two-tailed significance levels, generated by using a Monte Carlo method [27] with a number of 10,000 (if not otherwise mentioned) surrogate series. This method [27] was applied also to estimate the confidence intervals $(95 \%)$ for the regression of overall suicide on temperature, based on the frequency-structure of the residuals from a linear regression, calculated by Monte Carlo simulations. The model was built using the preprogram interval (segmented as 1751-1765, 1766-1780 ... 1976-1990) and was used to predict the temperaturedependent suicide rate for the segment 1991-2005 of the prevention program. Making use of the 15 -year periods served as a convenient analysis resolution over both the prevention program and pre-program intervals. The codes for calculations were adopted from a Monte Carlo methodology $[28,29]$ and are available at http://www.helsinki. fi/science/dendro/reconstats.html.

\section{Results}

In seeking to provide a comprehensive assessment of both temperature changes and suicides, we use the extraordinarily long suicide [17] and temperature [16] records of the region, which span the past 26 decades (1751-2008). These data record a total of 94,356 deaths from suicide over the 258 -year period. During the 18th and 19th centuries, the suicide rates remained below 10 (Fig. 1a). Thereafter, the rate exhibits increase with transient high values during the 1930s, whereas the next decade is characterized by relatively low rates. Since the early 1950 s, the suicide rates have been rising consistently for both sexes, and the rates culminate in a peak overall suicide rate of 30 in 1990. After that year, the suicide rates (both male and female) have been declining, this notable decrease in suicides overlapping temporally with the national suicide prevention program in Finland. Generally, the same features are observed in the data of suicide rates after variance stabilization and removal of the long-term trend and the series are presented as $z$-scores (Fig. 1b).

Positive correlations can be found between annual temperatures and suicide rates since 1751 (Supplementary material, Table S2). The climatic correlations are positive over pre-1936 and post-1936 sub-periods when the death certificates were predominantly written by a layman and a doctor, respectively (Table S2). It was also found that the climatic correlations were slightly higher over the early (1751-1936) rather than the late period (1936-1990) (Table S2). Moreover, the long-term variations in temperatures can consequently be linked with suicide rates up until the initiation of the prevention program (Fig. 2). This positive association indicates that the period of higher

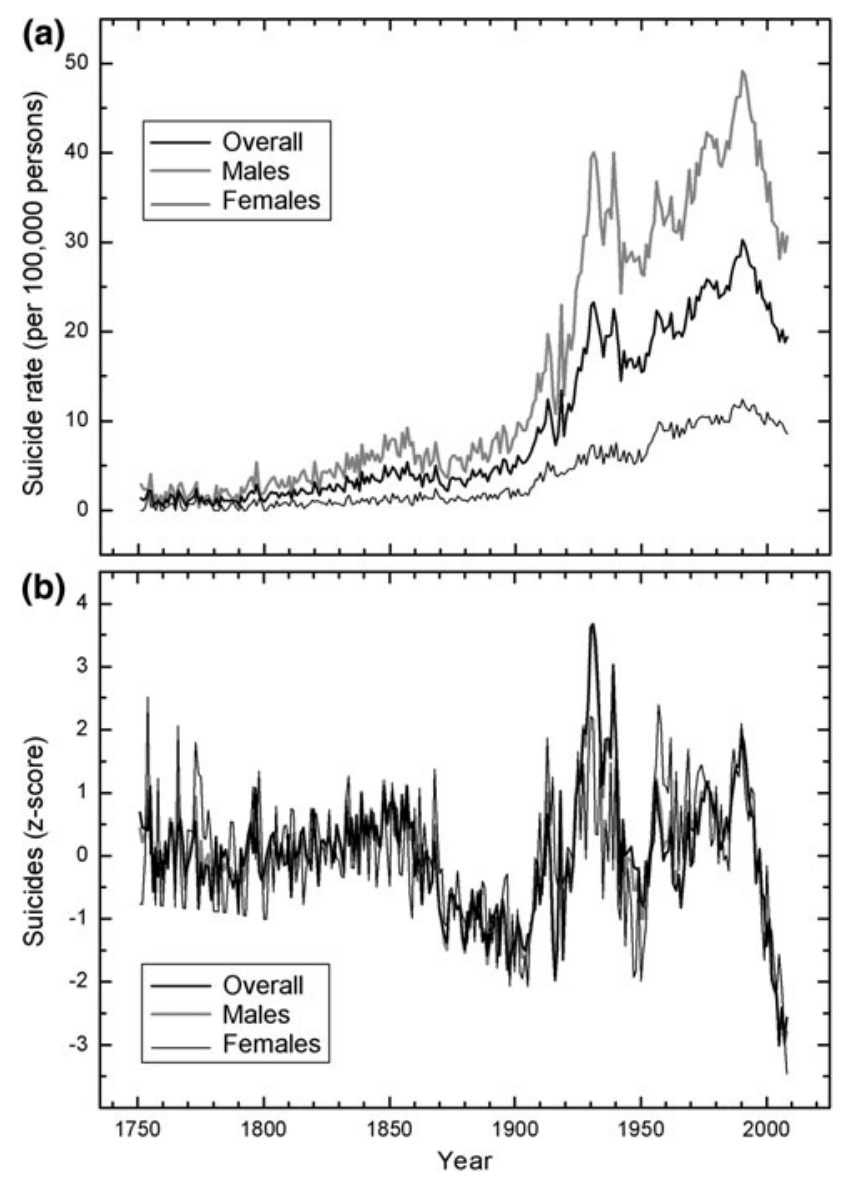

Fig. 1 Suicide variations of the 1751-2008 period. Initial suicide rates (a) were calculated relative to population changes and their transformations (b) relative to the changing variance and non-linear trends. See Supplementary material (Table S1) for descriptive statistics of data. $Z$-score refers to the number of standard deviations from the long-term mean of the series

suicide rate has coincided with the period of warmer temperatures in the study region. However, this correlation remains high and statistically significant only until the national suicide prevention program started in 1990. Since that year, the temperatures have warmed notably (this temperature departure from the long-term mean level exceeding three standard deviations; see Fig. 2), but the suicide rates have dropped.

Further examination of the data show that the temperature correlations improve when the comparison is carried out over longer time-scales (Fig. 3). The overall suicide rate and temperatures correlate with a coefficient of nearly 0.8 (Fig. 3). This translates into an estimate that the temperature variations could explain a surprising $60 \%$ of suicide variance before 1990 .

We next use the previously defined relationships between suicides and temperatures (Fig. 2) to predict a hypothetical temperature-mediated suicide rate since the initiation of the prevention program. The established 


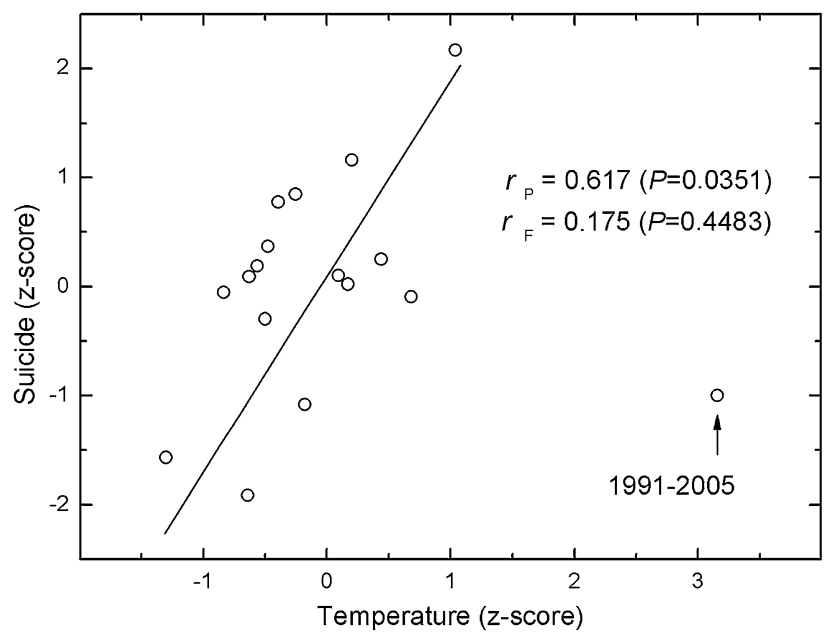

Fig. 2 Sensitivity of suicidal deaths to temperature fluctuations. Linear model quantifies the pre-program association using 15-year means of suicide rates and temperatures. Pearson correlations are shown both for the pre-program $\left(r_{\mathrm{P}}\right)$ (here, 1751-1990) and full $\left(r_{\mathrm{F}}\right)$ (here, 1751-2005) periods, with Monte Carlo [27] based statistical significance $(P)$. $Z$-score refers to the number of standard deviations from the long-term mean of the series

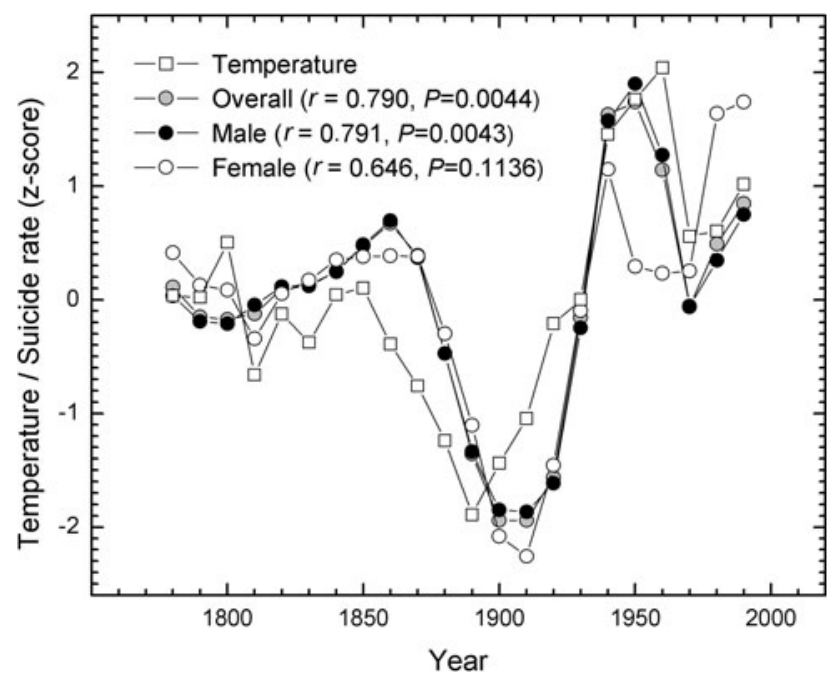

Fig. 3 Temporal variations in suicides and temperatures. The values are shown between 1751 and 1990 using 30-year means with 10-year step. The associations between suicide rates and temperature were quantified using Pearson correlations $(r)$ and the statistical significance $(P)$ of each correlation. The calendar year indicates the last year of the 30-year period. The significance was generated using a Monte Carlo method [27] with a number of $1,000,000$ surrogate series

warming ought to have increased the temperature-mediated suicide rate since 1991, but the suicide rate actually declined over the same period (Fig. 4). The average rate during the program was 24.3 suicides per 100,000 persons (1991-2005). This value was notably less than the suicide rate of 32.6 predicted by the temperature-dependent model. That is, the post-1990 period was anomalous with respect

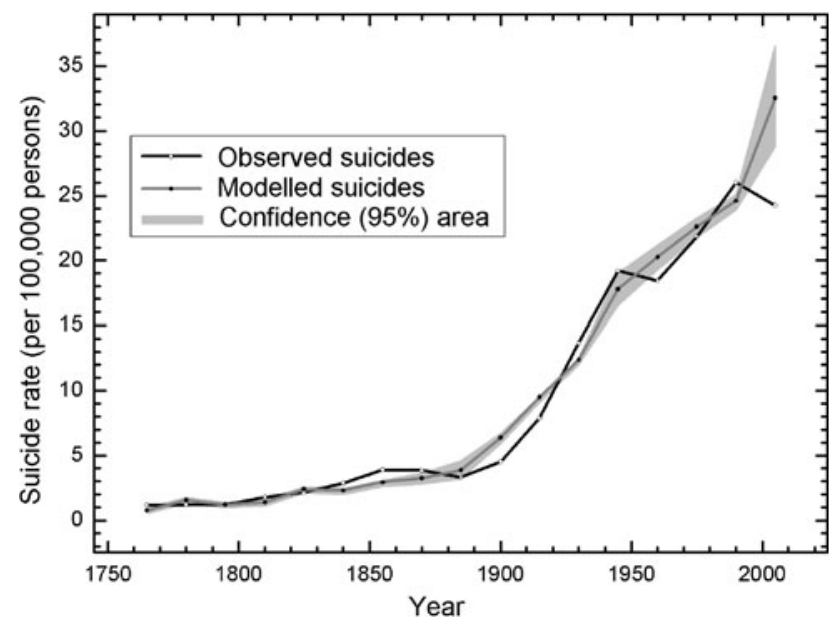

Fig. 4 Temporal fluctuations in observed and modeled suicide figures. The model was built using the relationship established above (shown as black line in Fig. 2), with the Monte Carlo based [28, 29] confidence area, and the series transformed back to the original scale using the inverse of the transformations that were applied to the data

to the association defined by the previous 240 years. The association between the temperatures and suicide rates, evident since the mid-eighteenth century, broke down during the prevention program.

\section{Discussion}

These multi-decadal associations show that a temperature trend of similar or longer duration can have a profound influence on the suicide rates in a region where the modern rate has been relatively high. It is crucial to note that climates that cover large areas are fluctuating on similar multi-decadal scales as recorded in the past $[30,31]$ and as predicted for the future [32]. The spatiotemporal coherence of the associations increases the value of our findings, as it could be speculated that present-day warming may alter the suicidal behavior in a manner similar to that of previous natural temperature changes.

Our data was given at an annual resolution and thus the seasonality, which is often discussed in the suicide literature [33-35], was beyond the scope of the analysis. Bearing in mind that climate refers to long-term weather statistics [36], the aim of this paper was not to analyze suicide mortality in the context of weather, but rather climate and long-term climatic evolution. Previous studies [37-39] have shown that the variations in the suicide rates could be statistically correlated with selected climate variables on varying spatial and temporal scales [5]. However, a literature review showed that our understanding of the climatic influence on suicidal behavior is still far from conclusive and in part contradictory [5]. One reason for remaining 
uncertainties could be the lack of socio-economic parameters in the analyses [40]. A statistical model taking into account socio-economic parameters, in addition to climate, could be theorized to provide a more detailed understanding.

Suicide datasets often come with temporal limitations as the series of suicide data are short relative to the climatic records. It may be that the assessments have remained conflicting, due probably to temporal limitations of the datasets. Our analyses provide evidence of principal importance and demonstrate the potential of temperature-mediated influence on suicidal behavior, thus confirming the findings of those studies showing that the temperature-suicide linkage might be widespread over national and cultural borders. A caveat in this respect is that we were unable to examine which types of suicides are associated with annual temperature. Also, the spatial representation of the results in the context of sub-regions within the country remained unspecified because of data limitations. It follows that our analyses thus provide an estimate for the total number of suicides in the country. Regarding the data limitations, it was possible to evaluate the results over the periods when the death certificates were predominantly written by laymen (before 1936) and doctors (since 1936). Doing so, it was seen that the correlations between the annual temperature and suicide rates were higher for the early sub-period when the death certificates were mostly written by a layman, rather than a doctor. This could indicate that the climatic associations derived in this study were not distorted by the issue of death certificates. Thus, the temporal privileges of our datasets [16, 17] enabled assessments at scales on which the ongoing warming distinctly operates and is correspondingly appropriate for policy responses to climate change.

Psychological autopsy studies have demonstrated that major depressive episodes contribute substantially to deaths from suicide [41]. In Hungary a depression-management educational program for general practitioners resulted in a significant decrease in suicide rates [42]. Although the annual suicide rate in Finland has decreased by $40 \%$ between 1990 and 2005 [9], we report here that suicide rates would have been expected to actually rise along with the climatic warming seen over the same period. During the period of 1991-2005, the annual sum of observed suicides averaged 1,248, whereas the modeled suicide rate of 32.6 per 100,000 persons over the same period translates into an annual estimate of 1,678 suicides (with a $95 \%$ confidence range of $1,485-1,882$ cases). The intervention could thus have resulted in a decrease of 240-630 suicides per year, given the multi-decadal temperature forcing on suicide mortality. While the program in Finland was the first comprehensive effort of its kind anywhere [11], our results underscore the favorability of implementing intervention programs elsewhere.

Below we propose a hypothesis which links temperature-mediated deaths from suicide to temperature-responsive brown adipose tissue (BAT) over-activity. To begin with, we want to acknowledge that it presents one potential mechanism by which a longer-term ambient temperature gradient may influence mood-related behaviors within a population, and that other plausible mechanisms are likely to exist as well. Our hypothesis herein suggests that the activation of BAT improves cold tolerance at the cost of heat tolerance, triggering anxiety and psychomotor agitation, and in the end affects mood in a negative way. We hypothesize that it is the compromised heat tolerance that predisposes to death from suicide. We give the following arguments in support of the hypothesis.

First, BAT is present and metabolically active in adults $[43,44]$ and is overactive in suicides associated with a depressive episode [45]. Second, once BAT has become metabolically active through temperature changes, it is more resistant to becoming quiescent [46] and may thereby contribute to the risk of suicide over a prolonged period. Third, BAT has physiological relevance in the majority of adult humans [47], and it seems that environmental (e.g. outdoor work) or lifestyle (e.g. alcohol abuse) factors clearly contribute to activation of BAT [48] and, if not paid attention to, these factors may easily over-activate BAT. In addition, BAT appears to be temporarily reactivated for heat production in compensation to the ageing-driven lowering of basal metabolic rate in the sixth decade of life [49]. It is of note that the suicide mortality peaks in Finland in both men and women are at the age of 45-59 years. Finally, a view that climatic factors, such as temperature and humidity, have a role in determining species distributions and influence phenotypic variation of populations over geographic space has gained support from population genetics. The genetic basis for adaptation to climate-mediated selection was elucidated in a scan of the human genome using 61 worldwide populations [50]. Among the strongest signals were genes that play roles in heat and cold tolerance, and there was an enrichment of strong correlations with climate variables for two sets of genes: first, genes that are differentially regulated in response to ultraviolet radiation, and second, genes that are central in the differentiation of brown adipocytes. These findings suggest that BAT is relevant to natural selection and therefore that disrupted BAT activity may influence adaptation and subsequently survival.

To further formulate our hypothesis we envisage a mechanism in which climatic warming favors the growth and maturation of BAT, i.e. triggers adult stem cells readily to initiate asymmetric division and give rise to transit amplifying cells. This mechanism is similar to the one 
described by Hazlerigg and Lincoln [51], with the exception that the effect of climatic warming is sustained, not cyclical, in nature. We propose that climatic warming incubates the reservoir of preadipocytes of the individual, leading to an increase in the proportion of individuals with inducible cells to differentiate into mature brown adipocytes. In the course of time, the proportions of those with activated BAT and those with over-activated BAT increase. Subsequently, an increasing proportion of the affected, i.e. those with the over-activated BAT, is predisposed to and at risk of suicide, and it is by this mechanism, unless preventive actions are taken, that climatic warming leads to an increase in suicide mortality within a population.

Currently, it cannot be ruled out that the central sensory circuits projecting from BAT to the brain $[52,53]$ might provide a pathway, through the ventromedial hypothalamus [54] to the periaqueductal gray areas $[55,56]$ that are key regions involved in anxiety [57, 58], which we hypothesize to mediate the effect of over-activated BAT in those affected. However, the over-activated BAT is tightly involved in abnormalities in the thermoregulatory mechanisms that characterize individuals prone to depressive episodes [59-62].

Temperature histories evidence long-term climatic trends and variations of shorter. These fluctuations may either be natural $[30,31]$ or anthropogenic [4]. Climate change will affect human health in many ways, but mostly in adverse ways [1-3]. Our results show the coherence of temperature-mediated deaths from suicide in a multi-centurial context. It could be reasoned that present-day warming influences suicidal behavior in a manner similar to that of previous natural temperature changes. Nevertheless, intervention resulted in a decrease in suicides, the results underscoring the favorability of implementing prevention programs. Man-made climate change may be irreversible for the forthcoming millennium [63], whereas the climate-related increase in suicides may be reversible.

\begin{abstract}
Acknowledgments We thank two anonymous reviewers for their comments on the earlier version of the manuscript, Tauno Tyllinen, Irmeli Penttilä and Sigmund Hov Moen for help during data compilation, and the Academy of Finland (122033, 217724) and Koneen Säätiö for funding.
\end{abstract}

Conflict of interest The authors declare they have no conflict of interest.

\section{References}

1. McGeehin MA, Mirabelli M. The potential impacts of climate variability and change on temperature-related morbidity and mortality in the United States. Environ Health Persp. 2001; 109(Suppl. 2):185-9.

2. Patz JA, Campbell-Lendrum D, Holloway T, Foley JA. Impact of regional climate change on human health. Nature. 2005;438: 310-7.

3. Haines A, Kovats RS, Campbell-Lendrum D, Corvalan C. Climate change and human health: impacts, vulnerability, and mitigation. Lancet. 2006;367:2101-9.

4. Intergovernmental Panel on Climate Change (IPCC), Climate change 2007: the physical science basis. Contribution of Working Group I to the fourth assessment report of the Intergovernmental Panel on Climate Change. Cambridge: Cambridge University Press; 2007.

5. Deisenhammer EA. Weather and suicide: the present state of knowledge on the association of meteorological factors with suicidal behaviour. Acta Psychiatr Scand. 2003;108:402-9.

6. Levi F, La Vecchia C, Lucchini F, Negri E, Saxena S, Maulik PK, et al. Trends in mortality from suicide, 1965-99. Acta Psychiatr Scand. 2003;108:341-9.

7. La Vecchia C, Lucchini F, Levi F, Negri E. Trends in suicide mortality in Europe, 1955-89. Soz Präventiv Med. 1993;38: 379-97.

8. Hawton K, van Heeringen K. Suicide. Lancet. 2009;373: $1372-81$.

9. Lönnqvist J. Suicide prevention in Finland. In: Wasserman D, Wasserman C, editors. Oxford textbook of suicidology and suicide prevention. A global perspective. Oxford: Oxford University Press; 2009. p. 793-5.

10. Upanne M, Hakanen J, Rautava M. Can suicide be prevented? The suicide project in Finland 1992-1996: Goals, implementation and evaluation. STAKES National Research and Development Centre for Welfare and Health. Gummerus Printing; 1999.

11. Wilson J. Finland pioneers suicide prevention. Ann Intern Med. 2004;140:853-6.

12. Näyhä S. Short and medium-term variations in mortality in Finland: a study on cyclic variations, annual and weekly periods and certain irregular changes in mortality in Finland during period 1868-1972. Scand J Soc Med. 1981;8 Suppl 21:1-101.

13. van Oldenborgh GJ, Drijfhout SS, van Ulden AP, Haarsma R, Severijns C, Hazeleger W, et al. Western Europe is warming much faster than expected. Clim Past. 2009;5:1-12.

14. Helama S, Holopainen J. Climate change and pure geography: proximity, landscape and cartography in the context of J.G. Granö's theory. Alue ja Ympäristö. 2010;39:3-14.

15. Holopainen J. Reconstructions of past climates from documentary and natural sources in Finland since the 18th century. PhD Dissertation. University of Helsinki; 2006.

16. Moberg A, Bergström H. Homogenization of Swedish temperature data. Part III: The long temperature records from Uppsala and Stockholm. Int J Climatol. 1997;17:667-99.

17. Holopainen J, Helama S, Partonen T. Memes and Finnish suicide. J Soc Med. 2010;47:174-86.

18. Suomen virallinen tilasto. Kuolemansyyt vuosina 1936-1937. Valtioneuvoston kirjapaino; 1939.

19. Suomen virallinen tilasto. Kuolemansyyt vuosina 1946-1950. Valtioneuvoston kirjapaino; 1955.

20. Suomen virallinen tilasto. Kuolemansyyt vuosina 1946-1950. Valtioneuvoston kirjapaino; 1959.

21. Partonen T, Haukka J, Viilo K, Hakko H, Pirkola S, Isometsä E, et al. Cyclic time patterns of death from suicide in northern Finland. J Affect Disorders. 2004;78:11-9.

22. Tuomenvirta H, Drebs A, Førland E, Tveito OE, Alexandersson $\mathrm{H}$, Laursen EV, et al. Nordklim data set 1.0 - description and illustrations. DNMI klima 08/01; 2001.

23. Brohan P, Kennedy JJ, Harris I, Tett SFB, Jones PD. Uncertainty estimates in regional and global observed temperature changes: a 
new dataset from 1850. J Geophys Res. 2006;111:D12106. doi: 10.1029/2005JD006548.

24. Cook ER, Peters K. Calculating unbiased tree-ring indices for the study of climatic and environmental change. Holocene. 1997;7:359-68

25. Cook E, Briffa K, Shiyatov S, Mazepa V. Tree-ring standardization and growth-trend estimation. In: Cook ER, Kairiukstis LA, editors. Methods of dendrochronology: applications in the environmental science. Dordrecth: Kluwer Academic Publishers; 1990. p. 104-23.

26. Jarque CM, Bera AK. A test for normality of observations and regression residuals. Int Stat Rev. 1987;55:163-72.

27. Ebisuzaki W. A method to estimate the statistical significance of a correlation when the data are serially correlated. J Climate. 1997;10:2147-53.

28. Macias Fauria M, Grinsted A, Helama S, Moore J, Timonen M, Martma T, et al. Unprecedented low twentieth century winter sea ice extent in the Western Nordic Seas since A.D. 1200. Clim Dyn. 2010;34:781-95.

29. Macias-Fauria M, Grinsted A, Helama S, Holopainen J. Persistence matters: estimation of the statistical significance of paleoclimatic reconstruction statistics from autocorrelated time series. Dendrochronologia. 2012;30:179-87.

30. Schlesinger ME, Ramankutty N. An oscillation in the global climate system of period 65-70 years. Nature. 1994;367:723-6.

31. Sutton RT, Hodson DLR. Atlantic Ocean forcing of North American and European summer climate. Science. 2005;309:115-8.

32. Stott PA, Kettleborough JA. Origins and estimates of uncertainty in predictions of twenty-first century temperature rise. Nature. 2002;416:723-6.

33. Partonen T, Haukka J, Nevanlinna H, Lonnqvist J. Analysis of the seasonal pattern in suicide. J Affect Disord. 2004;81:133-9.

34. Yang AC, Tsai S-J, Huang NE. Decomposing the association of completed suicide with air pollution, weather, and unemployment data at different time scales. J Affect Disord. 2011;129:275-81.

35. Müller H, Biermann T, Renk S, Reulbach U, Ströbel A, Kornhuber J, et al. Higher environmental temperature and global radiation are correlated with increasing suicidality - a localized data analysis. Chronobiol Int. 2011;28:949-57.

36. Pielke RA Sr. A broader view of the role of humans in the climate system. Phys Today. 2008;61:54-5.

37. Preti A. The influence of climate on suicidal behaviour in Italy. Psychiatr Res. 1998;78:9-19.

38. Ruuhela R, Hiltunen L, Venäläinen A, Pirinen P, Partonen T. Climate impact on suicide rates in Finland from 1971 to 2003. Int J Biometeorol. 2009;53:167-75.

39. Törő K, Dunay G, Bartholy J, Pongrácz R, Kis Z, Keller E. Relationship between suicidal cases and meteorological conditions. J Forensic Legal Med. 2009;16:277-9.

40. Tsai J-F. Socioeconomic factors outweigh climate in the regional difference of suicide death rate in Taiwan. Psychiatr Res. 2010;179:212-6.

41. Henriksson MM, Aro HM, Marttunen MJ, Heikkinen ME, Isometsä ET, Kuoppasalmi KI, et al. Mental disorders and comorbidity in suicide. Am J Psychiatr. 1993;150:935-40.

42. Szanto K, Kalmar S, Hendin H, Rihmer Z, Mann JJ. A suicide prevention program in a region with a very high suicide rate. Arch Gen Psychiatr. 2007;64:914-20.

43. Enerbäck S. Human brown adipose tissue. Cell Met. 2010;11:248-52.

44. Frontini A, Cinti S. Distribution and development of brown adipocytes in the murine and human adipose organ. Cell Metab. 2010;11:253-6.
45. Huttunen $\mathrm{P}$, Kortelainen ML. Long-term alcohol consumption and brown adipose tissue in man. Eur J Appl Physiol Occup Physiol. 1990;60:418-24.

46. Zukotynski KA, Fahey FH, Laffin S, Davis R, Treves ST, Grant $\mathrm{FD}$, et al. Seasonal variation in the effect of constant ambient temperature of $24{ }^{\circ} \mathrm{C}$ in reducing FDG uptake by brown adipose tissue in children. Eur J Nucl Med Mol Imag. 2010;37:1854-60.

47. Lee P, Greenfield JR, Ho KK, Fulham MJ. A critical appraisal of the prevalence and metabolic significance of brown adipose tissue in adult humans. Am J Physiol Endoc M. 2010;299:E601-6.

48. Huttunen P, Hirvonen J, Kinnula V. The occurrence of brown adipose tissue in outdoor workers. Eur J Appl Physiol Occup Physiol. 1981;46:339-45.

49. Heaton JM. The distribution of brown adipose tissue in the human. J Anat. 1972;112:35-9.

50. Hancock AM, Witonsky DB, Alkorta-Aranburu G, Beall CM, Gebremedhin A, Sukernik R, Utermann G, Pritchard JK, Coop G, Di Rienzo A. Adaptations to climate-mediated selective pressures in humans. PLoS Genet. 2011;7:e1001375.

51. Hazlerigg DG, Lincoln GA. Hypothesis: cyclical histogenesis is the basis of circannual timing. J Biol Rhythm. 2011;26:471-85.

52. Bartness TJ, Vaughan CH, Song CK. Sympathetic and sensory innervation of brown adipose tissue. Int J Obesity (London). 2010;34(Suppl. 1):S36-42.

53. Morrison SF, Nakamura K. Central neural pathways for thermoregulation. Front Biosci. 2011;16:74-104.

54. López M, Varela L, Vázquez MJ, Rodríguez-Cuenca S, González CR, Velagapudi VR, et al. Hypothalamic AMPK and fatty acid metabolism mediate thyroid regulation of energy balance. Nat Med. 2010;16:1001-8.

55. Beart PM, Nicolopoulos LS, West DC, Headley PM. An excitatory amino acid projection from ventromedial hypothalamus to periaqueductal gray in the rat: autoradiographic and electrophysiological evidence. Neurosci Lett. 1988;85:205-11.

56. Vaughan $\mathrm{CH}$, Bartness TJ. Anterograde transneuronal viral tract tracing reveals central sensory circuits from brown fat and sensory denervation alters its thermogenic responses. Am J Physiol Reg I. 2012;302:R1049-58.

57. Wilent WB, Oh MY, Buetefisch C, Bailes JE, Cantella D, Angle $\mathrm{C}$, et al. Mapping of microstimulation evoked responses and unit activity patterns in the lateral hypothalamic area recorded in awake humans: technical note. J Neurosurg. 2011;115:295-300.

58. Linnman C, Moulton EA, Barmettler G, Becerra L, Borsook D. Neuroimaging of the periaqueductal gray: state of the field. Neuroimage. 2012;60:505-22.

59. Farrell WJ, Alberts JR. Rat behavioral thermoregulation integrates with nonshivering thermogenesis during postnatal development. Behav Neurosci. 2007;121:1333-41.

60. Lkhagvasuren B, Nakamura Y, Oka T, Sudo N, Nakamura K. Social defeat stress induces hyperthermia through activation of thermoregulatory sympathetic premotor neurons in the medullary raphe region. Eur J Neurosci. 2011;34:1442-52.

61. Yee N, Plassmann K, Fuchs E. Juvenile stress impairs body temperature regulation and augments anticipatory stress-induced hyperthermia responses in rats. Physiol Behav. 2011;104:408-16.

62. Gilmer WS, McKinney WT. Early experience and depressive disorders: human and non-human primate studies. J Affect Disord. 2003;75:97-113.

63. Solomon S, Plattner G-K, Knutti R, Friedlingstein P. Irreversible climate change due to carbon dioxide emissions. P Natl Acad Sci USA. 2009;106:1704-9. 